\title{
Organosolv Fractionation of Waste Biomass for Lignin Production Enhanced by Oxygen
}

\author{
Jing Li, ${ }^{\mathrm{a}, \mathrm{b}, *}$ Huifang Zhao, ${ }^{\mathrm{a}}$ Xuejin Zhang, ${ }^{\mathrm{a}}$ and Chen Liang ${ }^{\mathrm{b}}$ \\ An oxygen-enhanced organosolv fractionation method to produce lignin \\ from waste biomass was investigated. In this novel biorefinery process, \\ mild conditions, i.e., temperature at 80 to $100{ }^{\circ} \mathrm{C}$ and pressure $<0.8$ \\ $\mathrm{MPa}$, were employed to alleviate energy input and to retain the original \\ lignin structure as much as possible. The results showed that the lignin \\ yield was increased with increasing process temperature, ethanol \\ concentration, and ratio of liquid to solid. Although little structural \\ changes were observed, the normalized Infrared transmittance results \\ revealed quantitative differences. Moreover, a basic kinetic study was \\ conducted, and the results showed that there existed two stages with \\ fast and slow rates during the delignification processes. Analysis of the \\ fibers' micro-structure also demonstrated the effectiveness of oxygen- \\ enhanced organosolv fractionation. However, a phenol-based inducer \\ could possibly further improve the efficiency based on the delignification \\ mechanism of reactive oxygen species, which will be studied in future \\ research.
}

Keywords: Organosolv; Oxygen; Lignin; Biorefinery

Contact information: a: School of Environmental and Natural Resources, Zhejiang University of Science and Technology, Hangzhou 310023, China; b: Guangxi Key Laboratory of Clean Pulp \& Papermaking and Pollution Control, College of Light Industry and Food Engineering, Guangxi University, Nanning 530004, China; *Corresponding author: ljing1987@ gmail.com

\section{INTRODUCTION}

Currently, most biorefinery processes focus on the cellulose and/or hemicellulose fractions, while not placing any priority on lignin, which is the only large-volume renewable aromatic feedstock (Song et al. 2019). However, biomass-based lignin has proved its wide applications in various aspects, such as carbon fibers (Kadla et al. 2002), adhesives (Çetin and Özmen 2002), and health care (Oihana et al. 2018). Therefore, it is still an urgent need to enhance the fractionation performance for efficient utilization of biomass and also lignin. Of all the possible fractionation processes, the organosolv method has demonstrated its success in lignin isolation due to its inherent advantages including high purity lignin production and solvent recycling. However, the process conditions are generally higher than $190{ }^{\circ} \mathrm{C}$ and longer than $60 \mathrm{~min}$ (Ke et al. 2016). Thus, it is necessary to introduce an efficient catalytic/assistant agent to enable the use of mild reaction conditions, which limit the degradation of cellulose and hemicellulose and produce a high yield of lignin.

There have been reported several historical studies on organosolv methods for lignin fractionation. The non-catalyst ethanol process has been basically adopted in the lignin extraction process. Besides, acid, base, and metal salts have also been used frequently as catalyzer to improve the process performance, such as $\mathrm{H}_{2} \mathrm{SO}_{4}, \mathrm{NaOH}$, $\mathrm{MgCl}_{2}$, and so on (Park et al. 2010). Comparatively, the lignin yield from processes with 
application of catalysts showed clear improvements, and the process conditions could be optimized and more energy-saving (Huijgen et al. 2011; Rossberg et al. 2019). With 210 ${ }^{\circ} \mathrm{C}$ and $50 \% \mathrm{w} / \mathrm{w}$ aqueous $\mathrm{EtOH}$, lignin yield reaches $84 \%$. However, using $30 \mathrm{mM}$ $\mathrm{H}_{2} \mathrm{SO}_{4}$ as catalysts, the process under conditions with a decrease of $20{ }^{\circ} \mathrm{C}$ and an increase to $60 \% \mathrm{w} / \mathrm{w}$ aqueous $\mathrm{EtOH}$ could achieve similar results (Wildschut et al. 2013). With the superior effect on hemicellulose hydrolysis, acid catalyzer can break the lignin carbohydrate linkages and therefore facilitate the lignin dissolution (Huijgen et al. 2011). Alkaline ethanol medium was shown to destroy the trihedral resonance structure of lignin through breakage of ether bond while the impregnation effect was improved, thereby enhancing the delignification (Bendzala and Kokta 1995; Shatalov and Pereira 2005; Huijgen et al. 2011). Moreover, various pretreatment methods could be integrated with ethanol for delignification. Autohydrolysis aimed at hemicellulose removal followed by ethanol treatment has been employed for lignin preparation (Moniz et al. 2015, 2018). The highest delignification yield reached $42 \%$ at optimal conditions of $60.5 \%$ ethanol for 24 h (Moniz et al. 2015). However, morphological characterization shows that the lignin migration and deposition on fiber surface during the hydrolysis process influences the lignin dissolution in ethanol, and therefore it lowers the fractionation efficiency (Li et al. 2019). Besides, ultrasound, steam explosion, and microwave have also been studied to assist delignification (Li et al. 2012; Duan et al. 2017).

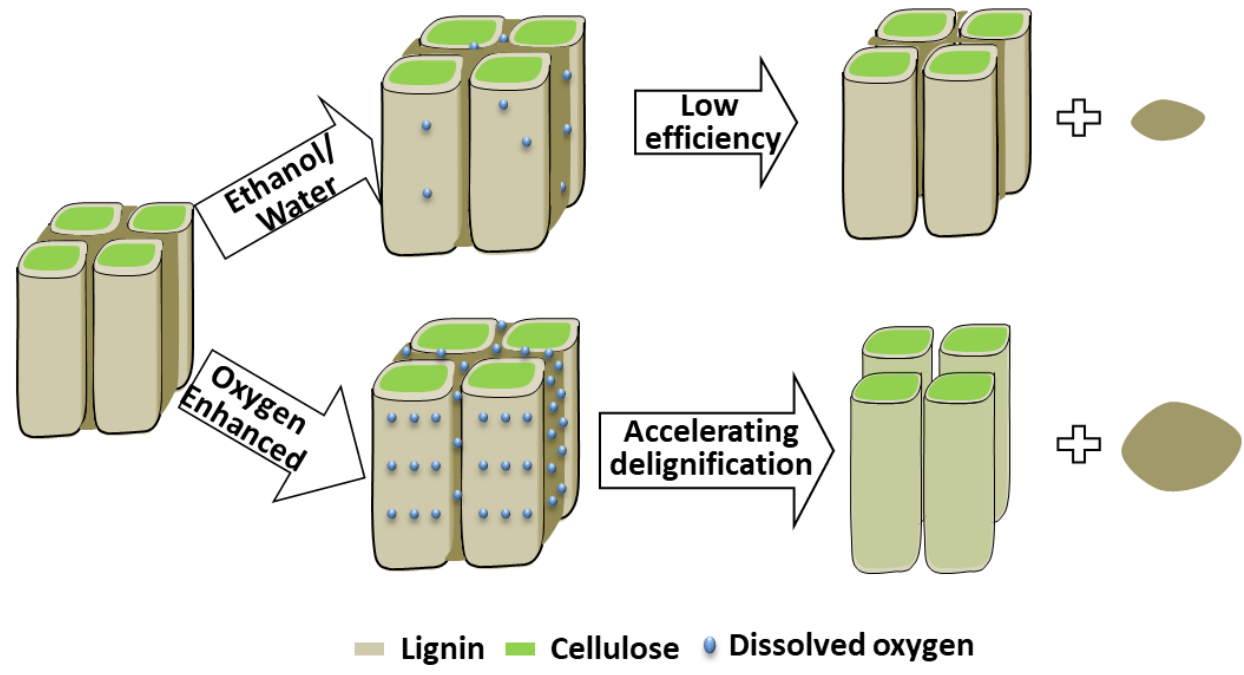

Fig. 1. Schematic mechanism of oxygen-enhanced ethanol system for lignin

Oxygen delignification in chemical pulping is an indispensable process for removal of residual lignin due to its comparatively higher selectivity (Li et al. 2016; Zhao et al. 2018). During this process, oxygen is first dissolved in the solution for production of activated oxygen species including peroxy radicals, hydroxyl radicals, and hydroperoxy radicals. Because the solubility of oxygen in ethanol $\left(25{ }^{\circ} \mathrm{C}, 101.325 \mathrm{kPa}\right.$ : $24.17 \mathrm{~mL} / 100 \mathrm{~mL})$ is about 8 times higher than that in water $\left(25^{\circ} \mathrm{C}, 101.325 \mathrm{kPa}: 2.831\right.$ $\mathrm{mL} / 100 \mathrm{~mL}$ ), the introduction of oxygen into the organosolv delignification system is possible. Based on this mechanism, a novel biorefinery process aimed at efficient lignin fractionation with mild energy input was investigated, and the mechanism is shown in Fig. 1. In this paper, the optimum process conditions were confirmed, and the basic delignification kinetics and possible improvement measures were considered.

Li et al. (2020). "Organosolv fractionation of biomass," BioResources 15(2), 2774-2783. 2775 


\section{EXPERIMENTAL}

\section{Materials}

Wheat straw was collected from a farm in Shandong Province, China. The raw material was mechanically pulverized and screened. The components between 40 and 60 mesh size were prepared by experimental grinder and stored in sealed containers for more than $24 \mathrm{~h}$ for water balance and further use. According to TAPPI T412 om-11 (2011a), TAPPI T211 om-07 (2007a), TAPPI T9 m-54 (1998), TAPPI UM250, TAPPI T222 om11 (2011b), and TAPPI T204 cm-07 (2007b), the content of moisture, ash, holocellulose, acid-soluble lignin (ASL), acid-insoluble lignin (AIL), and benzene-ethanol extractives (Ext) were determined, as shown in Table 1. Analytical-grade chemicals, including benzene, ethanol, sulphuric acid, etc., used in this paper were from commercial sources.

Table 1. Chemical Content of Wheat Straw Based on Oven-dried Biomass

\begin{tabular}{|l|c|c|c|c|c|c|}
\hline Component & Moisture & Ash & Holocellulose & ASL & AlL & Ext \\
\hline Content (\%) & 8.38 & 7.47 & 68.64 & 1.47 & 11.92 & 2.01 \\
\hline
\end{tabular}

\section{Oxygen-enhanced Ethanol Extraction Process of Lignin (OEEL)}

The extraction procedure of lignin from wheat straw is presented schematically in Fig. 2. The 40- to 60-mesh fraction of wheat straw was prepared with an experimental grinder. All of the organosolv fractionation experiments were carried out in batches in a laboratory autoclave system with industrial oxygen. First, $10 \mathrm{~g}$ of oven-dried wheat straw was placed in the autoclave, followed by the addition of ethanol according to the ratio of liquid to wheat straw from $15: 1$ to $25: 1$. Stirring was provided by a magnetic stir bar at the bottom of the vessels, and oxygen was introduced to the sealed vessel. The vessel was heated to the specific temperature $\left(80^{\circ} \mathrm{C}\right.$ to $\left.100{ }^{\circ} \mathrm{C}\right)$ and held for $1 \mathrm{~h}$. At the end of the reaction, the reactor was cooled to room temperature. The reacted wheat straw was transferred to a Buchner funnel with a stainless steel filter screen (200-mesh). The filtrates were rotary evaporated for ethanol recovery until only a small amount of highconcentration filtrates remained. The remaining filtrate was dropped into an excessive amount of acid water for lignin flocculation and then precipitation by centrifugation. The lignin sample was vacuum-dried at $45^{\circ} \mathrm{C}$.

\section{Characterization}

Lignin yield (\% w/w) was based on the amount of oven-dried lignin after vacuum drying divided by the amount of AIL in the raw material. Fourier transform infrared spectra (FT-IR) were recorded on spectrophotometer (8400S, Shimadzu, Kyoto, Japan). The number of scans was 32, and the resolution was $4 \mathrm{~cm}^{-1}$. The spectra were obtained within the range of 500 to $4000 \mathrm{~cm}^{-1}$ in the transmittance mode. The dissolved content of lignin in process liquor was analyzed by UV/Vis spectroscopy (UV2600, Shimadzu). According to the multiple factor of dilution, the absorbance at $280 \mathrm{~nm}$ was converted to results with the same times and used for the delignification kinetic study. A scanning electron microscope (SEM, S3400, Hitachi, Tokyo, Japan) was used to observe the surface morphology and microstructure of wheat straw after organosolv fractionation.

Li et al. (2020). "Organosolv fractionation of biomass," BioResources 15(2), 2774-2783. 2776 


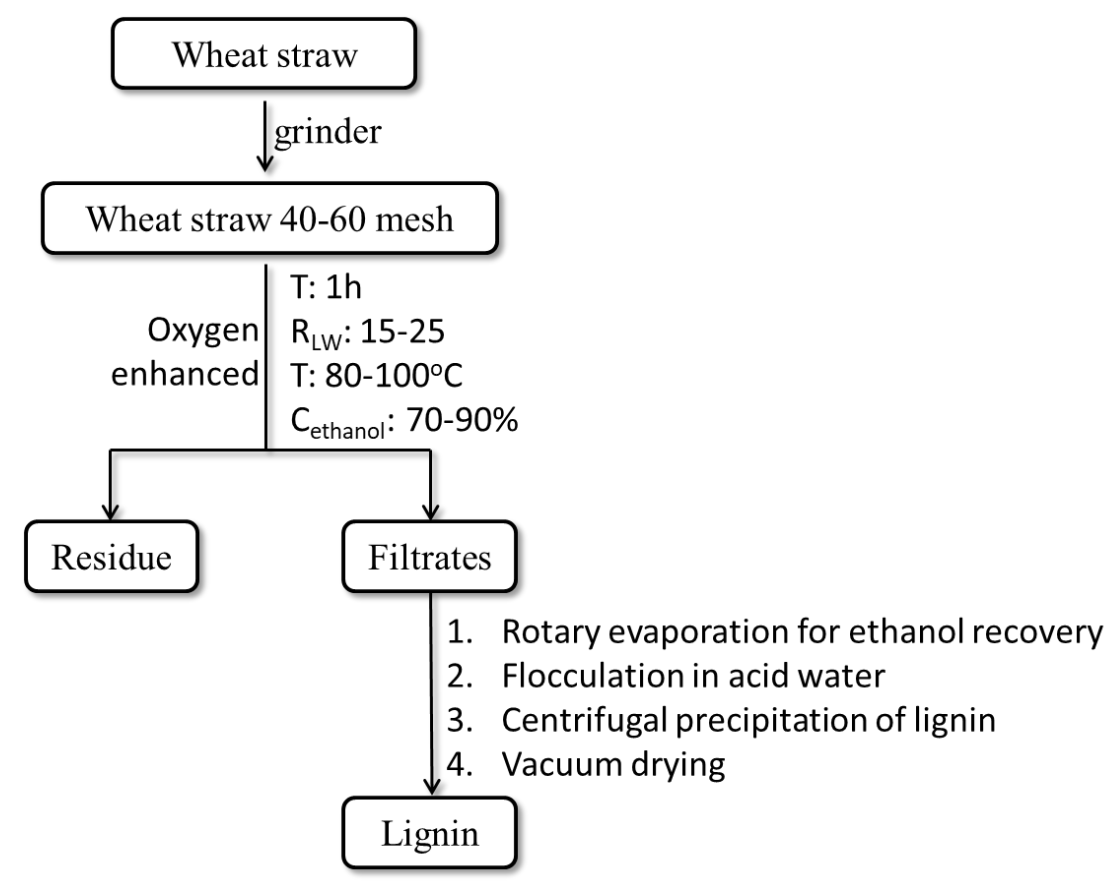

Fig. 2. Procedure of lignin fractionation from wheat straw with ethanol enhanced by oxygen

\section{RESULTS AND DISCUSSION}

\section{Effect of Process Conditions on Lignin Yield}

With the same energy input, an optimum lignin yield is the first priority for the newly developed organosolv processes enhanced by oxygen. The effects of process conditions including ratio of liquor to wheat straw, ethanol concentration (Cethanol), and temperature on lignin yield were investigated. Figure 3 presents the change of lignin yield with different ratio of liquor to wheat straw at different concentration of ethanol.

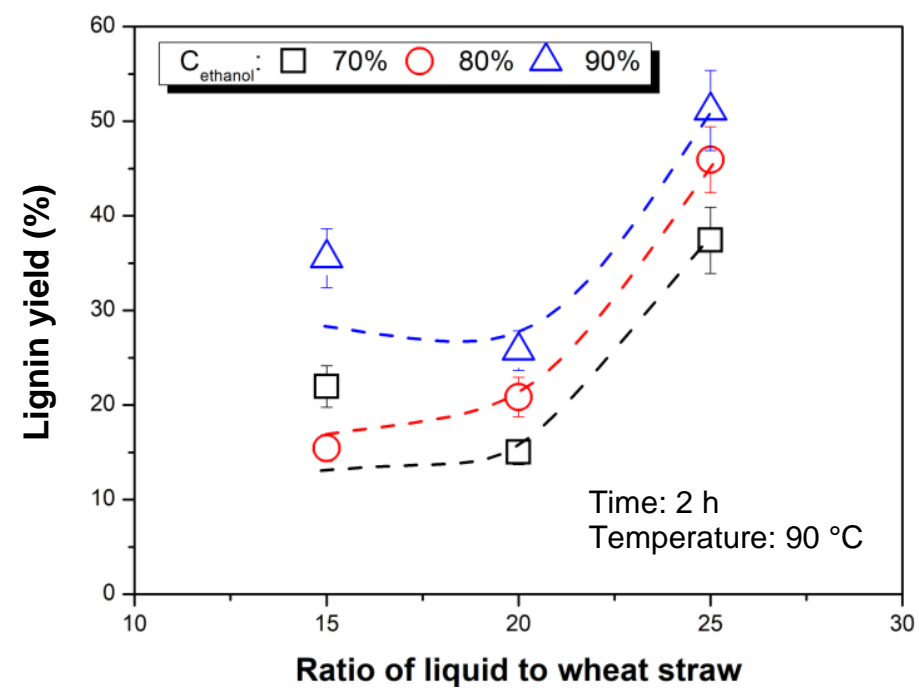

Fig. 3. Change of lignin yield as a function of ratio of liquid to wheat straw with different ethanol concentration during OEEL processes 
The lignin yield increased with increasing ethanol concentration from $70 \%$ to $90 \%$. Because the surface tension of ethanol $\left(0.0162 \mathrm{~N} / \mathrm{m}\right.$ at $\left.90{ }^{\circ} \mathrm{C}\right)$ is only about one fourth that of water $\left(0.0607 \mathrm{~N} / \mathrm{m}\right.$ at $\left.90{ }^{\circ} \mathrm{C}\right)$, ethanol can penetrate more easily into the straw interior. The higher occupation of ethanol in the process solution is better for delignification and dissolution of the compact raw materials. However, with the increase of ratio of liquor to wheat straw, the lignin yield was increased, which is also possibly due to easier dissolution. Moreover, with the same ratio of liquor to wheat straw at 25, the lignin yield increased by $22.8 \%$ and $11.3 \%$, respectively, with Cethanol from $70 \%$ to $80 \%$ and $80 \%$ to $90 \%$. Therefore, considering the energy input, the concentration at $80 \%$ was judged as the optimum choice.

Figure 4 shows the changes in lignin yield as a function of ratio of liquor to wheat straw under different process temperatures. Similar results from the change of ratio of liquor to wheat straw were observed. The temperature increase improved the delignification rate and was more effective with higher ratio of liquor to wheat straw. With ratio of liquor to wheat straw at 20 and 25 and temperature from $80{ }^{\circ} \mathrm{C}$ to $100{ }^{\circ} \mathrm{C}$, the lignin yield increased by $36.7 \%$ and $30.8 \%$, respectively. However, with ratio of liquor to wheat straw at 15 , the lignin yield results showed similar results at 80 to $100{ }^{\circ} \mathrm{C}$.

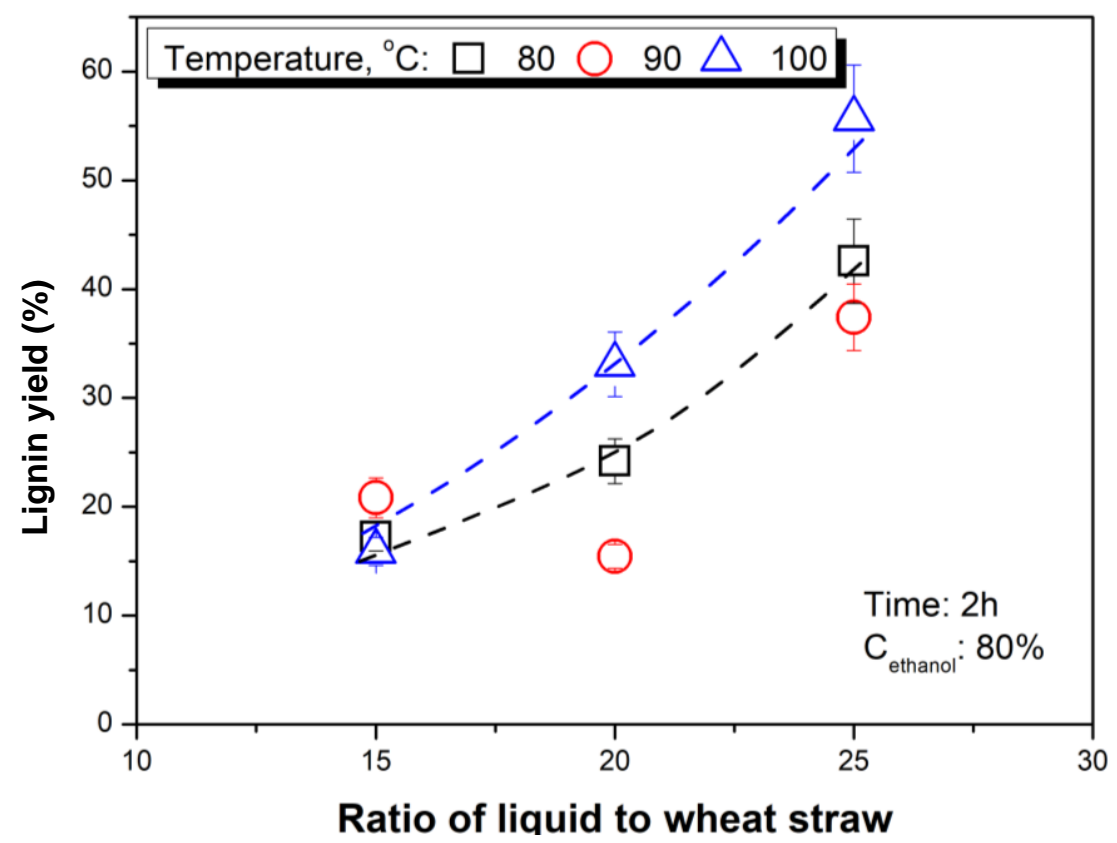

Fig. 4. Change of lignin yield as a function of ratio of liquor to wheat straw with different process temperature during OEEL processes

Figure 5 exhibits the lignin yield with different ethanol concentrations at different temperatures. Similar results were observed with change of temperature and ethanol concentration. With the increase of process temperature, the lignin yield was clearly enhanced, and the increased ethanol concentration also improved the lignin production. Moreover, at comparatively lower concentration of $70 \%$, the effect of temperature was small, and with the increase of concentration, the yield improvement was more remarkable for temperature increase from $80{ }^{\circ} \mathrm{C}$ to $90{ }^{\circ} \mathrm{C}$ than that from $90{ }^{\circ} \mathrm{C}$ to $100{ }^{\circ} \mathrm{C}$. 


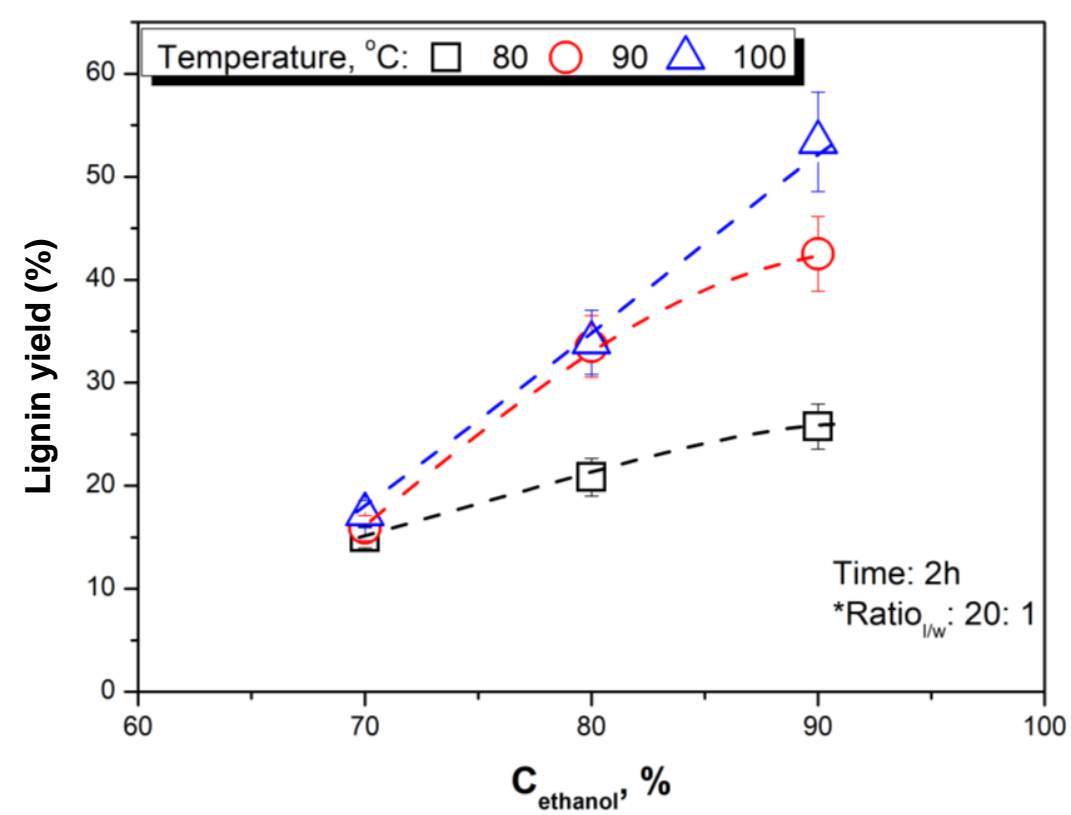

Fig. 5. Change of lignin yield as a function of Cethanol with different process temperature during OEEL processes. *Ratiol/w denotes ratio of liquor to wheat straw.

\section{Kinetic Study of OEEL Process}

To investigate the delignification mechanism, the ultra-violet (UV) absorbance at $280 \mathrm{~nm}$ was collected throughout the delignification process including the heating and holding stage, as shown in Fig. 6. For organosolv delignification process both with and without oxygen assistance, it can be divided into two stages with fast and slow delignification rate. Due to the lower surface tense of ethanol, the delignification rate can rapidly reach dynamic equilibrium. However, the fast delignification stage could last for about $30 \mathrm{~min}$ for OEEL process but only $10 \mathrm{~min}$ for process without oxygen. Therefore, larger quantities of lignin production from OEEL process were observed, as shown in Fig. 6. An improvement in delignification resulting from the temperature increase could also be demonstrated.

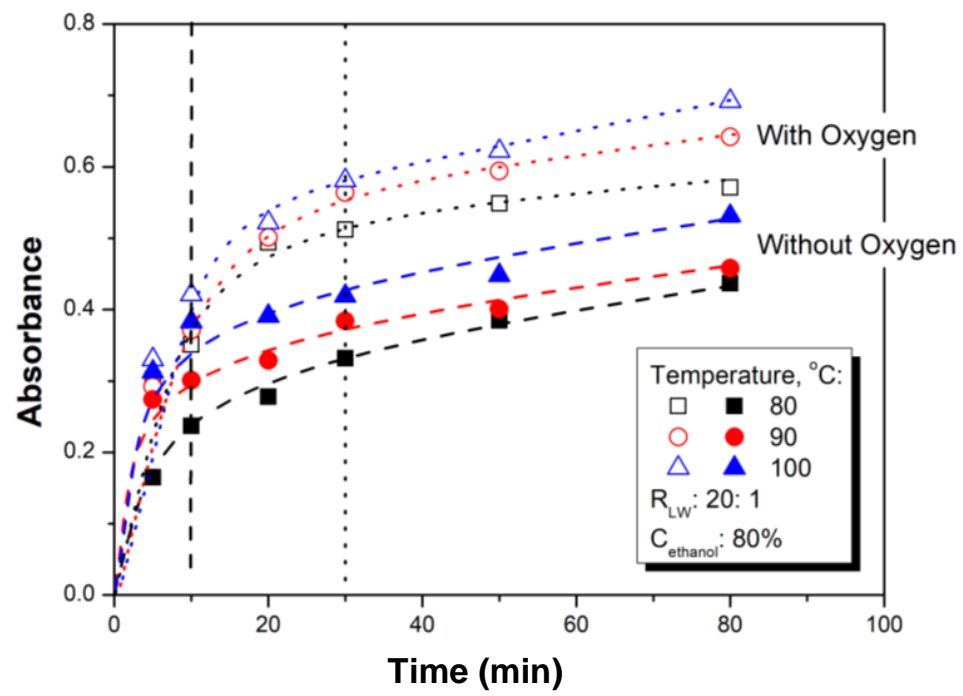

Fig. 6. Change of UV spectra at $280 \mathrm{~nm}$ of process liquor with time 


\section{Chemical Structure Description of Organosolv Lignin}

The normalized FT-IR spectra of organosolv lignin are illustrated in Fig. 7. The spectra of lignin from processes at different temperatures were similar, and there were no significant structural changes. The prominent band around $3400 \mathrm{~cm}^{-1}$ is attributed at the $\mathrm{O}-\mathrm{H}$ stretching vibrations and hydrogen bonding in phenolic and aliphatic structures. The peaks at $2922 \mathrm{~cm}^{-1}$ and $2853 \mathrm{~cm}^{-1}$ arise from $\mathrm{C}-\mathrm{H}$ stretching of $\mathrm{CH}_{2}-\mathrm{CH}_{3}$, and the signals at $1721 \mathrm{~cm}^{-1}$ and $1656 \mathrm{~cm}^{-1}$ are assigned to carbonyl $\mathrm{C}=\mathrm{O}$. Peaks at $1514 \mathrm{~cm}^{-1}$ and 1426 $\mathrm{cm}^{-1}$ are also attributed to aromatic rings from lignin. Moreover, peak in $1324 \mathrm{~cm}^{-1}$ region represents $\mathrm{C}=\mathrm{O}$ stretching of the syringyl units and $1232 \mathrm{~cm}^{-1}$ corresponded to $\mathrm{C}-\mathrm{C}, \mathrm{C}-\mathrm{O}$ and $\mathrm{C}=\mathrm{O}$ stretching of the guaiacyl units. Lastly, 1117 and $1041 \mathrm{~cm}^{-1}$ designate ether $\mathrm{C}-\mathrm{O}$ bonds (Li et al. 2012; Ramezani and Sain 2018).

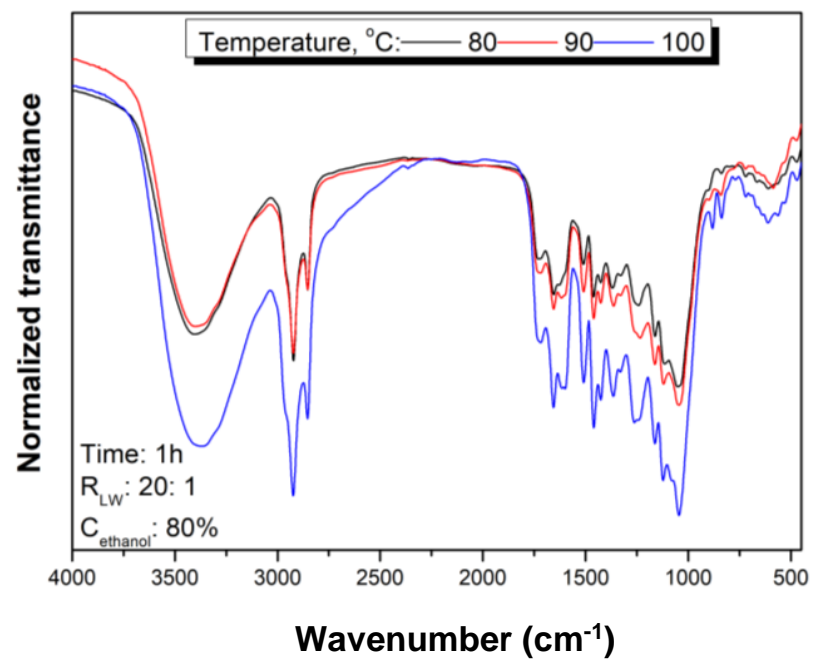

Fig. 7. Normalized FT-IR spectra (divided by transmittance at $2250 \mathrm{~cm}^{-1}$ ) of lignin from OEEL process at different temperatures

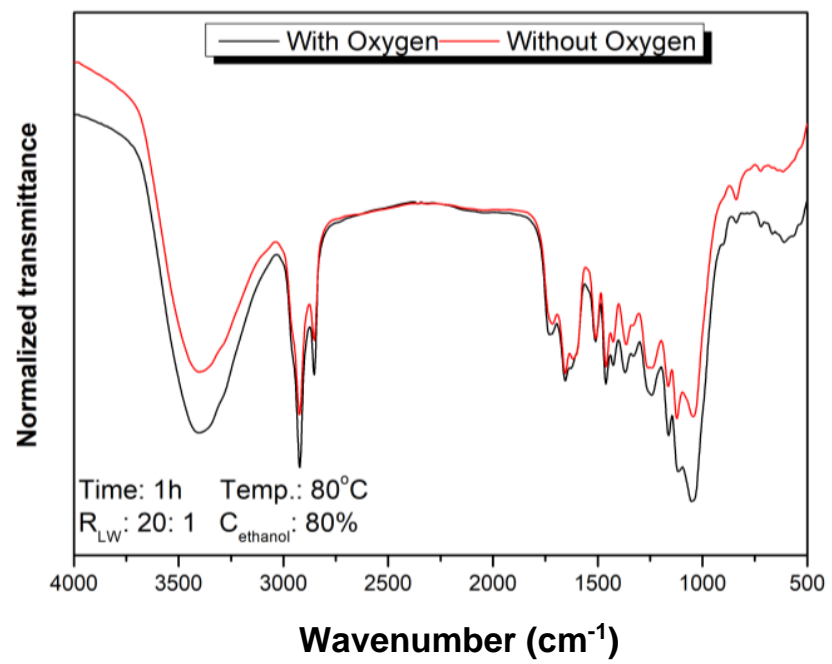

Fig. 8. Normalized FT-IR spectra (divided by transmittance at $2250 \mathrm{~cm}^{-1}$ ) of organosolv lignin with and without oxygen assistance

To verify the signal changes and diminish the weight difference of samples, the normalization method was applied for the FT-IR results, as shown in Fig. 7. The signal 
became stronger with the increase of the process temperature, which is in agreement with the previous results. Moreover, the difference of normalized spectra from organosolv lignin with and without oxygen assistance was also investigated, as shown in Fig. 8. There was a stronger signal for organosolv lignin with oxygen assistance.

\section{Micro-structure Analysis}

As shown in Fig. 9, in the structure of wheat straw after OEEL process, the fiber bundles disintegrated to some extent. However, it was also expected that the surrounding lignin remained on the fiber surface, meaning that there are still quantities of residual lignin from the raw materials but not the re-precipitation in the fractionation process. Thus, based on the oxygen delignification mechanism in the chemical pulping process, a phenol-based inducer may be more effective for initiation of oxygen transformation to effective delignification radicals including peroxy radicals, hydroxyl radicals, hydrogen peroxide anion, peroxy anion, etc., which will be considered in future research.

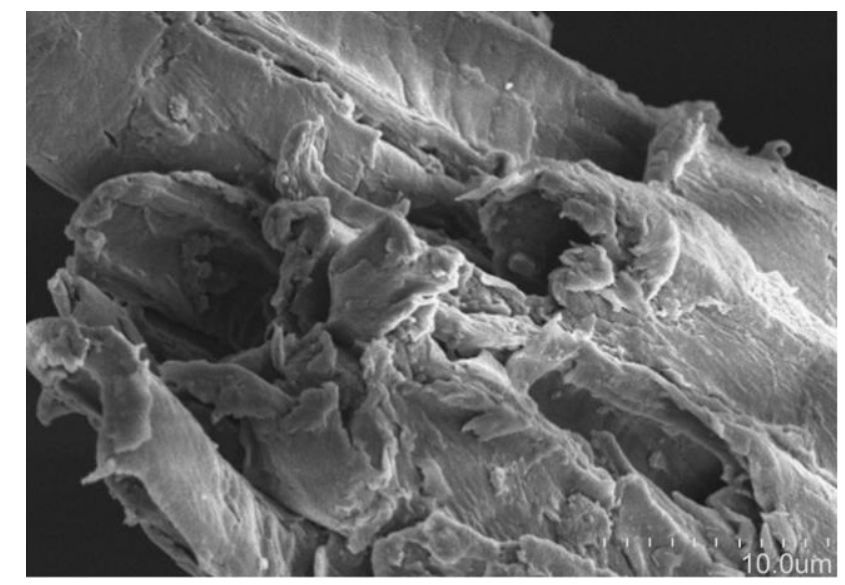

Fig. 9. Microscope structure of wheat straw after OEEL process

\section{CONCLUSIONS}

1. An oxygen-enhanced organosolv biorefinery process for lignin production with lignocellulosic biomass was introduced in this work. Mild process conditions were employed for alleviating energy input while keeping the lignin structure as original as possible.

2. The effect of process conditions on lignin yield and structure were investigated, while a quantitative difference of structural changes was also studied by normalized infrared transmittance. Kinetic studies revealed a two-stage process with fast and slow delignification rates.

\section{ACKNOWLEDGMENTS}

The authors are grateful for the support of the National Natural Science Foundation of China (Grant No. 21808209), the Zhejiang Provincial Natural Science Foundation of China (Grant No. LQ18C160003), and the Open Foundation of Guangxi Key Laboratory of Clean Pulp \& Papermaking and Pollution Control (No. KF201816-3). 


\section{REFERENCES CITED}

Bendzala, J., and Kokta, B.V. (1995). “Optimization and fundamentals of high-yield pulping with ethanol," Wood Science and Technology 29, 467-479. DOI:

10.1007/BF00194205

Çetin, N. S., and Özmen, N. (2002). "Use of organosolv lignin in phenol-formaldehyde resins for particleboard production: I. Organosolv lignin modified resins," International Journal of Adhesion \& Adhesives 22(6), 477-480. DOI: 10.1016/S01437496(02)00058-1

Duan, D., Zhao, Y., Fan, L., Dai, L., Lv, J., Ruan, R., Wang, Y., and Liu Y. (2017). "Low-power microwave radiation-assisted depolymerization of ethanol organosolv lignin in ethanol/formic acid mixtures," BioResources 12(3), 5308-5320. DOI: 10.15376/biores.12.3.5308-5320

Huijgen, W. J., Smit, A. T., Reith, J. H., and Uil, d. H. (2011). "Catalytic organosolv fractionation of willow wood and wheat straw as pretreatment for enzymatic cellulose hydrolysis," Journal of Chemical Technology and Biotechnology 86(11), 1428-1438. DOI: $10.1002 /$ jctb.2654

Kadla, J. F., Kubo, S., Venditti, R. A., Gilbert, R. D., Compere, A. L., and Griffith, W. (2002). "Lignin-based carbon fibers for composite fiber applications," Carbon 40(15), 2913-2920. DOI: 10.1016/S0008-6223(02)00248-8

Ke, Z., Pei, Z., and Wang, D. (2016). "Organic solvent pretreatment of lignocellulosic biomass for biofuels and biochemicals: A review," Bioresource Technology 199, 2133. DOI: 10.1016/j.biortech.2015.08.102

Li, J., Feng, P., Xiu, H., Li, J., Yang, X., Ma, F., Li, X., Zhang, X., Kozliak, E., and Ji, Y. (2019). "Morphological changes of lignin during separation of wheat straw components by the hydrothermal-ethanol method," Bioresource Technology 294, 122157-122163. DOI: 10.1016/j.biortech.2019.122157

Li, J., Zhang, C.Y., Hu, H.C., and Chai, X.S. (2016). "Effect of shortening kraft pulping integrated with extended oxygen delignification on biorefinery process performance of eucalyptus," Bioresource Technology 202, 119-124. DOI: 10.1016/j.biortech.2015.11.074

Li, M. F., Sun, S.-N., Xu, F., and Sun, R. C. (2012). "Ultrasound-enhanced extraction of lignin from bamboo (Neosinocalamus affinis): Characterization of the ethanol-soluble fractions," Ultrasonics Sonochemistry 19(2), 243-249. DOI:

10.1016/j.ultsonch.2011.06.018

Moniz, P., Lino, J., Duarte, L. C., Roseiro, L. B., Boeriu, C. G., Pereira, H., and Carvalheiro, F. (2015). "Fractionation of hemicelluloses and lignin from rice straw by combining autohydrolysis and optimised mild organosolv delignification,"

BioResources 10(2), 2626-2641. DOI: 10.15376/biores.10.2.2626-2641

Moniz, P., Serralheiro, C., Matos, C. T., Boeriu, C. G., and Carvalheiro, F. (2018). "Membrane separation and characterisation of lignin and its derived products obtained by a mild ethanol organosolv treatment of rice straw," Process Biochemistry 65, 136-145. DOI: 10.1016/j.procbio.2017.11.012

Oihana, G., René, H., Marwa, Y., Sedef, 1., Murat, K., and Jalel, L. (2018). "Potential use of kraft and organosolv lignins as a natural additive for healthcare products," $R S C$ Advances 8, 24525-24533. DOI: 10.1039/c8ra02255k

Park, N., Kim, H. Y., Koo, B. W., Yeo, H., and Choi, I. G. (2010). “Organosolv pretreatment with various catalysts for enhancing enzymatic hydrolysis of pitch pine

Li et al. (2020). "Organosolv fractionation of biomass," BioResources 15(2), 2774-2783. 2782 
(Pinus rigida)," Bioresource Technology 101, 7046-7053. DOI:

10.1016/j.biortech.2010.04.020

Ramezani, N., and Sain, M. (2018). "Thermal and physiochemical characterization of lignin extracted from wheat straw by organosolv process," Journal of Polymers \& the Environment 26(7), 3109-3116. DOI: 10.1007/s10924-018-1199-2

Rossberg, C., Janzon, R., Saake, B., and Leschinsky, M. (2019). "Effect of process parameters in pilot scale operation on properties of organosolv lignin," BioResources 14(2), 4543-4559. DOI: 10.15376/biores.14.2.4543-4559

Shatalov, A. A., and Pereira, H. (2005). "Kinetics of organosolv delignification of fibre crop Arundo donax L," Industrial Crops and Products 21(2), 203-210. DOI: 10.1016/j.indcrop.2004.04.010

Song, W. L., Dong, Q., Hong, L., Tian, Z., Tang, L., Hao, W., and Zhang, H. (2019). "Activating molecular oxygen with $\mathrm{Au} / \mathrm{CeO}_{2}$ for the conversion of lignin model compounds and organosolv lignin," RSC Advances 9, 31070-31077. DOI: $10.1039 / \mathrm{c} 9 \mathrm{ra} 04838 \mathrm{c}$

TAPPI T204cm-07. (2007b). "Solvent extractives of wood and pulp," TAPPI Press, Atlanta, GA.

TAPPI T211 om-17. (2007a). "Ash in wood, pulp, paper and paperboard: Combustion at $252^{\circ} \mathrm{C}$," TAPPI Press, Atlanta, GA.

TAPPI T222 om-11. (2011b). “Acid-insoluble lignin in wood and pulp,” TAPPI Press, Atlanta, GA.

TAPPI T412 om-11. (2011a). "Moisture in pulp, paper, and paperboard," TAPPI Press, Atlanta, GA.

TAPPI T9 m-54. (1998). "Holocellulose in wood," TAPPI Press, Atlanta, GA.

TAPPI UM 250. "Acid-soluble lignin in wood and pulp," TAPPI Press, Atlanta, GA. Wildschut, J., Smit, A. T., Reith, J. H., and Huijgen, W. J. (2013). "Ethanol-based organosolv fractionation of wheat straw for the production of lignin and enzymatically digestible cellulose," Bioresource Technology 135, 58-66. DOI: 10.1016/j.biortech.2012.10.050

Article submitted: December 9, 2019; Peer review completed: February 1, 2020; Revised version received and accepted: February 29, 2020; Published: March 3, 2020.

DOI: 10.15376/biores.15.2.2774-2783 